\title{
Attitudes of a Mediterranean population to the truth-telling issue
}

\author{
P Dalla-Vorgia, K Katsouyanni, T N Garanis, G Touloumi, P Drogari, A Koutselinis \\ University of Athens Medical School and Athens School of Public Health
}

\section{Authors' abstract}

The attitudes of the Greeks, a Mediterranean population, to the issue of telling the truth to the patient have been studied. There is no clear answer to the question: 'Do the Greeks wish to be informed of the nature of their illness?'. The answer is: 'It depends'. It depends on age, education, family status, occupation, place of birth and residence and on whether or not they are religious people. However, it does not depend on their sex - men and women have similar reactions to the issue of truth-telling. Although the present study shows lower percentages of those who wish to know the truth than studies on other populations, the conclusion is that, emphasising the need for good communication between doctors and patients, doctors should not lie, but should disclose to their patients the part of the truth they are ready to accept.

\section{Introduction}

The issue of telling the patient the truth about his/her illness, or withholding it from him/her, being closely connected as it is, with social factors, philosophical ideas, cultural background and even political aspects, has been treated in many and various ways depending on time and place.

In most countries until the late 50 s it was the 'primum non nocere' doctrine which prevailed, the first concern of doctors being to provide medical benefits rather than to respect the autonomy of the patient (1). It was with the trials of malpractice in the United States and the great importance given to informed consent that this attitude started to change. Also the big societal changes that took place in most countries gave people a better understanding of themselves and their rights. Respect for the patient and his right to autonomy took precedence over the paternalistic view that 'the doctor knows best and he can act in the way he believes to be in the patient's best interest'. In Greece, the motherland of Hippocrates, hippocratic tradition prevails even today, and the basic maxim that the doctor's first responsibility must be to benefit and not to harm the patient governs medical practice and

\section{Key words}

Truth-telling. explains the often paternalistic treatment of patients by Greek doctors (2). Although disclosure of the truth to the patient is a prerequisite for valid consent, lack of which might result in an offence to personal freedom and injury or offence to an individual (3), a few years ago in Greece it was very rare for the cancer patient, for example, to know what he was suffering from. The belief that the Greeks, as a Mediterranean people, are very sentimental, cannot accept a cruel truth and might react very badly was - and still is - shared by many doctors. The aim of the present study was to examine the views of the Greeks themselves on the issue of telling the patient the truth about his illness.

\section{Subjects and methods}

Five hundred questionnaires were gathered from apparently healthy people who had either: (a) visited a health centre at Areopolis (a small village in Southern Greece); (b) were members of a friendship club in Athens; (c) attended a seminar on health statistics in Athens (mostly health care professionals); (d) attended a course on epidemiology (third-year medical students at the University of Athens); (e) attended a course on public health (second-year students at the Technological Institute of Athens).

Information on basic demographic and socioeconomic variables was recorded, ie age, place of birth and residence, years of schooling, profession and marital status. The questionnaire included a question on whether the person's father and mother were alive; if they had died, we asked the cause of death. We also asked whether the respondent had suffered the loss of a beloved person recently (for example five years) and the cause of death. Afterwards, we asked whether the respondent considered him or herself a religious person and how often he/she went to church. Finally, we asked the main questions:

(i) Do you believe that when someone is seriously ill and it is certain (almost 100 per cent) that he will die soon (for example in a few months) the doctor should tell him the truth?

(ii) Do you believe that when someone is seriously ill and it is very probable (for example 50 per cent) that he will die, but not very soon (for example five years) the doctor should tell him the truth? 
(iii) Do you believe that when someone is seriously ill and has a relatively low probability (for example 10 per cent) of dying, the doctor should tell him the truth?

Possible answers were: 'Yes'; 'No'; 'It depends'.

\section{Results}

Table 1 (all tables are shown at the end of the paper) shows the distribution of subjects, by various sociodemographic factors, according to their reply to the question: 'Do you believe that when someone is seriously ill and it is certain (almost 100 per cent) that he will die soon (for example in a few months) the doctor should tell him the truth?'.

Variability by gender was not statistically significant.

Age was statistically very significant: A greater percentage of younger people replied 'Yes' and 'It depends', while a smaller percentage of older people replied 'No'.

Family status also had a high statistical significance. A greater percentage of married people replied 'No', compared to unmarried, and a smaller percentage of people with children, replied 'No', compared to people without children.

Education was statistically very significant. A greater percentage of people with higher education replied 'It depends'. Occupation also had a high statistical significance; a higher percentage of professionals (except health professionals) replied 'It depends', while a higher percentage of others (except students) replied 'No'.

A higher percentage of doctors replied 'It depends', compared to all others (except health professionals and students) a higher percentage of whom replied 'No'.

Places of birth and residence were statistically very significant. A greater percentage of people who were born and/or lived in urban areas replied 'It depends', while those who were born and/or lived in rural areas answered 'No' more frequently.

The self-perception of a person as religious or not is associated with the reply but does not reach nominal significance $(P=0.10)$. A greater percentage of religious people answered 'No', while a greater percentage of non-religious people answered 'It depends'.

Previous death of the mother was associated with the reply to a very statistically significant degree: 51.4 per cent of those who had lost their mother replied 'No' to the truth-telling question. The loss of the father is associated, to a less statistically significant degree, with answers ( 41.0 per cent replied 'No').

Table 2 shows the distribution of subjects, by various socio-demographic factors, according to their reply to the question: 'Do you believe that when someone is seriously ill and it is very probable (for example 50 per cent) that he will die, but not very soon (for example in five years) the doctor should tell him the truth?
Gender was not associated to a statistically significant degree with the answer to the above question, while age and family status were again statistically very significant.

Education also had high statistical significance; a greater percentage of people with lower education replied 'No'.

Occupation did not influence the answers to this question to a statistically significant degree. However, a very statistically significant percentage of doctors, as compared to all others (except students) replied 'It depends'.

Places of birth and residence had a very statistically significant influence on the answers to this question, too. People who were born and/or lived in a rural or semi-urban area replied 'No' much more frequently than people who were born and/or lived in an urban area.

Religion influenced the answer to this question to a statistically significant degree. People who were religious answered 'No' more frequently than nonreligious people, who answered 'It depends' more frequently.

People whose mother had died answered 'No' to a statistically significant degree; the loss of their father did not influence the answer to this question.

Table 3 shows the distribution of subjects, by various socio-demographic factors, according to their reply to the question: 'Do you believe that when someone is seriously ill and has a relatively low probability (for example 10 per cent) of dying, the doctor should tell him the truth?'

Neither gender nor age seemed to influence to a statistically significant degree the reply to this question. Family status had a low statistical significance.

Education was very statistically significant; more people with lower education replied 'No'. Occupation did not seem to influence the reply to this question, however, doctors replied 'Yes' less frequently, compared to all others (except health professionals and students) to a highly statistically significant degree.

Place of birth did not influence the reply to this question, while the statistical significance of the place of residence was only indicative.

Religion and the loss of a beloved person were not statistically significant.

Linear discriminant analysis was applied in order to assess the independent association of each variable studied, as well as its contribution to the differentiation and classification of subjects into groups according to their reply to the first truth-telling question.

The Statistical Package for the Social Sciences (SPSS) was used for this analysis. The following variables were included: age; gender; years of schooling; place of residence (in two categories: urban and semi-urban/rural); whether the mother was alive or not; whether the person had any children; whether the person was religious or not, and occupation (in two categories: doctors or other). Two statistically 
significant $(P<0.04)$ linear functions were computed, to discriminate among the three groups (those who replied 'Yes', 'No', 'It depends'). The groups can be described on the basis of these functions as follows: (a) People who replied 'No' tended to be older; to have relatively low educational levels; to have semi-urban/ rural places of residence; to have children and not to be doctors. (b) People who replied 'Yes' tended to be younger with relatively low educational levels (maybe still students); to live in an urban area; not to be doctors (however, they might be medical students). (c) In the group of people who answered 'It depends' there were sub-groups with distinctly different characteristics. So, one sub-group included well-educated young people who lived in urban areas, did not have children and tended not to be doctors. The second group included older people, also highly educated, who tended to live in non-urban areas and who also tended to be doctors. The other variables which were studied, ie gender, and whether the person was religious or not, had no significant contribution to the discrimination among groups.

\section{Discussion}

This survey reveals public attitudes to the issue of truth-telling. As is seen from the analysis of the data, one cannot give a clear answer to the question: 'Do the Greeks wish to be informed of the nature of their illness and its outcome?'. The existence of diverse opinions makes only one conclusion possible: 'It depends'. It depends on age, education, family status, occupation, place of birth and residence, on whether the participants are religious or not, and even on whether their parents are still alive. It seems, however, that the answer does not depend on their sex - men and women have similar reactions to the issue of truth-telling.

In the first question, to do with death being almost certainly imminent in a short period of time, young persons who, because of their age, view death from a distance, show more courage and reply 'Yes, the patient should be told the cruel truth'. Inhabitants of urban areas also reply 'Yes'. These people give as justifying reasons the need for the person to put his affairs in order, to say goodbye to his relatives and friends, to fulfil his last wishes and, thus, to leave this life content. Again, in connection with the first question, with death ante portas (meaning that death is very close), older people who have children of their own and who have had a different experience of life and death, believe that the truth about approaching death should not be told. The fact that people who replied 'No' to this question were of lower education and resided in rural/semi-urban areas can be reasonably explained: these people are, to a certain extent, deprived of the different perspective which education and life in a big urban centre can offer to the individual. 'It depends' is the answer of doctors who come into contact daily with different patients and who prefer to adjust their attitude according to the patient they have in front of them. It seems that Greek doctors are practising (even without realising it) a form of act utilitarianism, that is to say they consider the consequences of telling the truth, taking into account the peculiarities of each case, not accepting the moral rule of veracity as an absolute one (4). 'It depends' is also the answer of younger or older people with higher education. Educated people are in a better position to understand the role of psychological and socioeconomic factors in the formation of an opinion regarding such matters: they believe that the disclosure of truth should depend on the psychological and mental status of the patient, his character and temperament, his ability to keep his self control, his age ('Yes' say younger people, 'No' say older people), the nature of the disease, and even on the doctor's certainty concerning diagnosis and prognosis.

The significance of the loss of a beloved person (especially a mother) is quite intriguing: it seems that the experience of watching a family member suffering in the knowledge of death and the feeling of being doomed, in other words deprived of the privilege of hope, makes a lot of people reject truth-telling. Perhaps the realisation of their own grief during the period of terminal illness of a beloved one and the inherent personal sacrifices, make the respondents feel that when a case is fatal, ignoring the truth may in the long run be the best and most humane approach.

The second question carries the notion of death, but in a more distant time. The person has a serious probability (for example 50 per cent) that he will die but not very soon (for example in five years). The answer 'Yes' is more frequent for all groups of people than it was in the first question, but the differences between the answers are not so evident. The participants gave as a reason for replying 'Yes' the impetus a patient needs in order to co-operate better with his doctors, to be more careful with his health, and to fight with more strength for his life.

In the third question where someone is seriously ill but has a relatively low probability (for example 10 per cent) of dying, the answer 'Yes' is also much more frequent in all groups of people, the differences between answers being even smaller. Only education and the doctoral profession have a high statistical significance. More people of lower educational levels insist on the answer 'No', and although more doctors say 'Yes', they are much behind all others.

The significance of religion, which is evident especially in the first two questions, can be explained as follows: religious people tend to reject truth-telling because their main concern is the well-being of the patient (the 'Christian spirit') and not respect for his autonomy. They prefer, thus, to follow the way which entails less psychological pain for the person concerned and greater peace of mind. It is questionable, however, whether ignorance of the truth and a hopeless struggle for life can contribute to such peace (5).

The reasons the participants give for preferring truth-telling in this case are that knowing the truth can help the patient to be more careful and to follow his 
doctor's instructions; to organise his life in a better way and to defer, through changing his life-style, the time of death for as long as possible.

In general, the reasons given to justify truth-telling can be described as sentimental. It is remarkable that the word 'rights' is not invoked. As the field of medical ethics is still relatively limited in Greece, patient autonomy remains a vague or even unknown idea. The majority of patients are unaware of their rights and often let doctors decide on their behalf. Even younger and better educated people who tend to support truthtelling do not base their answers on notions such as autonomy, free choice or the right to decide what shall be done to one's own body, but rather on their feelings. Although it could be argued that such personal feelings, once analysed, are not very distant from the above-mentioned philosophical concepts, they are mostly based on practical attitudes to life. The survey thus confirms that Greek people lack not only the requisite theoretical background concerning their rights, but also the knowledge of the consequences of this lack for themselves in the health sector. This is quite relevant to the nature of a medical decision. Disclosing the truth means that the patient gets all the information she needs in order to decide about her body and her life. In other words, she is given the data which is necessary for the evaluation of the quality of her future life, the value of the medical intervention proposed and the calculation of the inherent risks. By refraining from telling the truth the doctor assumes the responsibility for these evaluations. He feels - or it has been imprinted in his mind - that he is solely responsible for making such decisions. This attitude, which is the prevailing one, has many elements of paternalism in it. From a different point of view it could also be argued that the doctor has the disadvantage of taking on his shoulders the whole burden of responsibility, whereas this responsibility should be shared.

This paternalism is revealed by the percentage of doctors who support truth-telling, a percentage which is indeed significant but which remains rather low compared to other categories of participants. This can be explained in many ways: firstly, doctors act for the benefit of their patients, their decisions being based more on their good conscience and instinct and less - or not at all - on the theory of medical ethics. Secondly, they often assume that most patients cannot fully understand what is being said to them and that, therefore, their understanding of their situation is inaccurate or distorted. This attitude derives from the perennial problem of communication between the professional and the patient, a problem which most doctors tend to 'solve' by not communicating at all. Thirdly, they are afraid that the disclosure of truth to a terminally ill patient might lead him to depression or to an absolute refusal of treatment. To a Greek, refusal of treatment might not be simply characterised as an unusual attitude but also as an irrational one: this is a subtle distinction with thorny ethical ramifications (6).
This argument expresses the conflict between the doctor's duties of beneficence and non-maleficence: telling the truth is a necessary prerequisite for an informed and valid consent but, on the other hand, what if it can have deleterious effects? Also, from a legal point of view, the attitude of non-disclosure is 'encouraged' by the fact that - as the extent of medical litigation is still very limited in Mediterranean countries - Greek doctors do not feel obliged to disclose the truth in the same way American or British doctors would. Even when they do, it is questionable how much they tell patients. Moreover, they often take the view that patients do not really want to know and that often they waive the right to know.

The issue of truth-telling has been examined thoroughly by many authors (7-15) with many arguments for and against disclosure of the truth. One of the decisive factors involved in telling or not telling the truth is the patients' wish, since doctors must respect their patient's wishes. It seems that many surveys (16-19) show that a high proportion of patients wish to know the truth. According to our study a smaller proportion wish to know the truth.

Among all those studied, 33.4 per cent replied 'Yes' to the first question, 34.2 per cent 'No' and 32.4 per cent 'It depends'. To the second question 43.9 per cent replied 'Yes', 35.0 per cent 'No' and 21.1 per cent 'It depends'. To the third question 50.1 per cent replied 'Yes', 34.7 per cent 'No' and 15.2 per cent 'It depends'.

Should our conclusion be that most Greeks prefer not to know the truth about their illness? Should doctors continue to conceal the truth from them and not even ask for their consent to a serious treatment? In our opinion the answer should be 'No'. But in order to establish a similar mentality amongst the medical profession, education is necessary. Education not only of the doctors, but of the public as well. Doctors must learn that truth-telling is indeed an alternative to the practice that has been followed until today, an alternative with many difficulties but also with advantages. The main difficulty is the personal relationship between doctor and patient: telling the truth entails a humane approach to the patient on the part of the doctor, an approach which requires great professional and individual maturity. The advantages consist not only in respecting the patient's autonomy but also in the building of a relationship of trust and fidelity between the two parties. On the other hand the public must become aware of their rights and their responsibilities concerning their health. Education in medical ethics would guide the doctors as to how and when to reveal the truth and would help the patients to understand and accept it.

\section{Acknowledgement}

The authors wish to thank Professor H Koutis of the Technological Institute of Athens, and Ms Th Kotinopoulou, registered nurse, Aeropolis Health Centre, for their help during the collection of the questionnaires. 
Panagiota Dalla-Vorgia, Dr Med Sc, is a Lawyer and Assistant Professor in the Department of Hygiene and Epidemiology, University of Athens Medical School. Klea Katsouyanni, Dr Med Sc, Giota Touloumi and Potitsa Drogari are, respectively, Assistant Professor and Biostatistician, Research Fellow and Biostatistician, and Chief Technician, in the Department of Hygiene and Epidemiology, University of Athens Medical School. Tina $N$ Garanis is a Lawyer and a Research and Teaching Fellow in the Department of Public and Administrative Health, Athens School of Public Health. Professor Antonios Koutselinis is Director of the Department of Forensic Medicine and Toxicology, University of Athens Medical School.

\section{References}

(1) Silverman W A. The myth of informed consent: in daily practice and in clinical trials. Fournal of medical ethics 1989; 15: 6-11.

(2) Dalla-Vorgia P. La tradizione ippocratica in Grecia. KOS. 1989; 47/48: 10-16 (in Italian with an English summary).

(3) Koutselinis A, Dalla-Vorgia P. Should the patient be informed of the nature of his illness? First International Conference: Philosophy, methodology, ethics and economics in clinical cancer research. Kos, Greece. 14-18 May 1986.

(4) Beauchamp T L, Childress J F. Principles of biomedical ethics (2nd ed). New York, Oxford: Oxford University Press, 1983: 26.

(5) Higgs R. Truth at last - a case of obstructed death. Fournal of medical ethics 1982; 8: 48-50.
(6) Brock D W, Wartman S A. When competent patients make irrational choices. New England journal of medicine 1990; 322: 1595-1599.

(7) Hartman N. Ethics. New York: Humanities Press, 1932.

(8) Henderson H J. Physician and patient as a social system. New England journal of medicine 1935; 212: 819-823.

(9) Kubler-Ross E. On death and dying. London: Tavistock, 1970.

(10) Bok S. Truth telling II. In: Reich W T, ed. Encyclopaedia of bioethics. New York: Free Press, 1978.

(11) Edmund-Davies, Lord. Telling the truth. In: Duncan A S, Dunstan G R, Welbourn R B, eds. Dictionary of medical ethics. London: Darton, Longman and Todd, 1981.

(12) Purtilo R, Cassel C. Ethical dimensions in the health professions. Philadelphia: W B Saunders and Co, 1981: 73-82.

(13) Lockwood M, ed. Moral dilemmas in modern medicine. Oxford: Oxford University Press, 1985: 187-202.

(14) Gillon R. Philosophical medical ethics. Chichester: John Wiley and Sons, 1986: 100-105.

(15) Seedhouse D. Ethics: the heart of health care. Chichester: John Wiley and Sons, 1988: 136-137.

(16) Aitken-Swan J, Easson E C. Reactions of cancer patients on being told their diagnoses. British medical journal 1959; i: 779-783.

(17) McIntosh J. Patients' awareness and desire for information about diagnosed but undisclosed malignant disease. Lancet 1976; ii: 300-303.

(18) Kelly W D, Friesen S R. Do cancer patients want to be told? Surgery 1950; 27: 822-826.

(19) Sprung C L, Winick B J. Informed consent in theory and practice: legal and medical perspectives on the informed consent doctrine and a proposed reconceptualization. Critical care medicine 1989; 17: 1346-1354. 


\section{Table 1}

Distribution of subjects (in absolute numbers and percentages) according to their reply to the question: 'Do you believe that when someone is seriously ill and it is certain (almost 100 per cent) that he will die soon (for example in a few months) the doctor should tell him the truth?', by various socio-demographic factors.

\section{GENDER}

Male

Female

AGE

$-25$

26-35

$36-45$

$46-55$

$56+$

\section{FAMILY STATUS}

Married

Unmarried

With children

Without children

\section{EDUCATION}

-6 yrs schooling

$7-12$

$12+$

Professionals

All others (except students)

Doctors

All others (except health

professionals and students)

\section{PLACE OF BIRTH}

Rural, semi-urban

Urban

\section{PLACE OF RESIDENCE}

Rural, semi-urban

Urban

\section{RELIGIOUS}

Yes

No

\section{LOSS OF BELOVED PERSON}

Mother

Father

\section{OCCUPATION}

(except health professionals)

\section{YES \\ n $(\%)$}

$88(35.8)$

$79(31.1)$

$46(43.0)$

$34(30.1)$

$44(32.8)$

$23(30.3)$

$17(26.2)$

92(32.4)

$65(35.7)$

$89(31.0)$

$78(36.6)$

$14(27.5)$

$42(40.0)$

$110(32.3)$

29(34.9)

$80(33.2)$

$10(21.7)$

$109(33.6)$

$61(32.4)$

$101(33.1)$

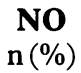

$76(30.9)$

$95(37.4)$

$13(12.1)$

$39(34.5)$

$46(34.3)$

$32(42.1)$

$40(61.5)$

\section{IT DEPENDS $\mathrm{n}(\%)$}

$82(33.3)$

$80(31.5)$

$48(44.9)$

$40(35.4)$

$44(32.8)$

$21(27.6)$

$8(12.3)$

$<0.001$

$117(41.2)$

39(21.4)

$124(43.2)$

$47(22.1)$

$75(26.4)$

$78(42.9)$

$<0.001$

$74(25.8)$

$88(41.3)$

$<0.001$

$35(68.6)$

$45(42.9)$

$89(26.1)$

2( 3.9$)$

$18(17.1)$

$142(41.6)$

$<0.001$

$18(21.7)$

$114(47.3)$

$10(21.7)$

$132(40.7)$

$36(43.4)$

$47(19.5)$

$26(56.5)$

$83(25.6)$

$<0.001$

$<0.001$

44(23.4)

$118(38.7)$

$<0.001$
^ Statistically non-significant
$42(65.6)$

$129(29.6)$

$6(9.4)$

$156(35.8)$

$<0.001$

$108(29.9)$

$48(38.7)$

$<0.10$

$33(26.6)$

$54(51.4)$

$117(29.7)$

$19(18.1)$

$<0.001$

$143(36.3)$

$<0.05$

$82(41.0)$

$59(29.5)$
Yes $\quad 59(29.5)$

$89(29.8)$

$103(34.4)$ 


\section{Table 2}

Distribution of subjects (in absolute numbers and percentages) according to their reply to the question: 'Do you believe that when someone is seriously ill and it is very probable (for example 50 per cent) that he will die, but not very soon (for example in five years) the doctor should tell-him the truth?', by various sociodemographic factors.

\section{GENDER}

Male

Female

\section{AGE$$
-25
$$$$
\text { 26-35 }
$$$$
36-45
$$$$
46-55
$$$$
56+
$$

\section{FAMILY STATUS}

Married

Unmarried

With children

Without children

\section{EDUCATION}

-6 yrs schooling

$7-12$

$12+$

\section{OCCUPATION}

Professionals

(except health professionals)

All others (except students)

Doctors

All others (except health

professionals and students)

\section{PLACE OF BIRTH}

Rural, semi-urban

Urban

\section{PLACE OF RESIDENCE}

Rural, semi-urban

Urban

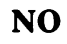

n(\%)

$88(35.8)$

$89(35.2)$

19(17.8)

$39(34.5)$

$49(36.6)$

$31(40.8)$

$38(58.5)$
96(33.9)

$78(42.9)$

94(32.9)

89(41.8)

$13(25.5)$

$42(40.0)$

$126(37.1)$

$29(35.4)$

87 (36.1)

$10(21.7)$

$116(35.9)$

68(36.2)

$111(36.5)$

$119(42.0)$

43 (23.6)

$122(42.7)$

$55(25.8)$

$32(62.7)$

$43(41.0)$

$101(29.7)$

$30(36.6)$

$107(44.4)$

$11(23.9)$

$137(42.4)$

$83(44.1)$

92(30.3)

$37(55.8)$

$140(32.2)$

136(37.8)

$43(34.7)$
136(37.8)

$36(29.0)$

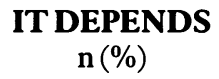

$70(28.5)$

$69(27.3)$

$37(34.6)$

$33(29.2)$

$37(27.6)$

$21(27.6)$

$10(15.4)$

$<0.001$

$68(24.0)$

61 (33.5)

$<0.001$

$70(24.5)$

69(32.4)

$<0.001$

6(11.8)

$20(19.0)$

$113(33.2)$

$<0.001$

$23(28.0)$

$47(19.5)$

$25(54.3)$

$70(21.7)$

$<0.001$

NS

$37(19.7)$

$101(33.2)$

$<0.001$

6( 9.4)

$133(30.6)$

$<0.001$

$88(24.4)$

$45(36.3)$

$<0.05$

$51(48.6)$

$22(21.0)$

$126(32.1)$

$80(40.0)$

$117(29.8)$

$53(26.5)$

$86(28.9)$

$97(32.6)$
Father

Yes

$67(33.5)$

* Statistically non-significant 


\section{Table 3}

Distribution of subjects (in absolute numbers and percentages) according to their reply to the question: 'Do you believe that when someone is seriously ill and has a relatively low probability (for example 10 per cent) of dying, the doctor should tell him the truth?', by various socio-demographic factors.

\section{GENDER}

Male

Female

-25
$26-35$
$36-45$
$46-55$
$56+$

FAMILY STATUS

Married

Unmarried

With children

Without children

\section{EDUCATION}

-6 yrs schooling

7-12

$12+$

\section{OCCUPATION}

Professionals

(except health professionals)

All others (except students)

Doctors

All others (except health

professionals and students)

\section{PLACE OF BIRTH}

Rural, Semi-urban

Urban

PLACE OF RESIDENCE

Rural, Semi-urban

Urban

\section{RELIGIOUS}

Yes

No

LOSS OF BELOVED PERSON

Mother

Father
AGE

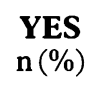

$125(51.0)$

$125(49.2)$

$51(47.7)$

$53(46.9)$

$74(55.6)$

$37(48.7)$

$31(47.7)$

$146(51.6)$

$92(50.5)$

$139(48.6)$

$111(52.1)$

$21(41.2)$

49(46.7)

$177(52.1)$

$43(51.8)$

$121(50.4)$

$19(41.3)$

$164(50.8)$

99(52.9)

$146(47.9)$

$33(51.6)$

$217(49.9)$

183(50.8)

$59(47.6)$

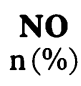

$82(33.5)$

$91(35.8)$

$33(30.8)$

$40(35.4)$

$41(30.8)$

29(38.2)

29 (44.6)

$105(37.1)$

$53(29.1)$

$111(38.8)$

$62(29.1)$

29(56.9)

$42(40.0)$

$102(30.0)$

29(34.9)

$92(38.3)$

$11(23.9)$

$121(37.5)$

\section{IT DEPENDS $\mathrm{n}(\%)$}

$38(15.5)$

$38(15.0)$

$23(21.5)$

$20(17.7)$

$18(13.5)$

$10(13.2)$

$5(7.7)$

$32(11.3)$

$37(20.3)$

$<0.05$

$36(12.6)$

$40(18.8)$

$<0.05$

$1(2.0)$

$14(13.3)<0.001$

$61(17.9)$

$11(13.3)$

$27(11.2)$

16(34.8)

$38(11.8)$

$<0.001$

$21(11.2)$

$55(18.0)$

NS

$104(34.1)$

28(43.8)

$145(33.3)$

3( 4.7$)$

$73(16.8)$

$<0.10$

$126(35.0)$

42 (33.9)

$51(14.2)$

23(18.5)

NS

$11(10.5)$

$65(16.5)$

$24(12.0)$

$52(17.4)$

$\begin{array}{rrrr}\text { Yes } & 108(54.0) & 68(34.0) & 24(12.0) \\ \text { No } & 142(47.7) & 104(34.9) & 52(17.4)\end{array}$

